\title{
Mulheres e mães do Bolsa Família: acesso à informação, empoderamento e cidadania em três comunidades de Sergipe
}

\author{
Acácia Rios \\ Universidad Complutense de Madrid, Facultad de Ciencias de la Documentación, \\ Madrid, España \\ acaciarios@gmail.com \\ Aurora Cuevas-Cerveró \\ Universidad Complutense de Madrid, Facultad de Ciencias de la Documentación, \\ Madrid, España \\ auro.cuevas@gmail.com \\ Ronaldo Linhares \\ Universidade Tiradentes, Programa de Pós-Graduação em Educação, \\ Aracaju, SE, Brasil \\ nuneslinhares.ronaldo8@gmail.com
}

DOI: https://doi.org/10.26512/rici.v12.n3.2019.26763

Recebido/Recibido/Received: 2018-11-15

Aceitado/Aceptado/Accepted: 2019-09-14

Resumo: O objetivo deste trabalho é apresentar o modelo metodológico INFORMENTO (Acesso à Informação e Empoderamento para a Igualdade e a Cidadania), desenvolvido na investigação Mulheres e mães do Programa Bolsa Família: acesso à informação, empoderamento e cidadania. Um estudo de três comunidades de Sergipe (2017) para analisar as entrevistas qualitativas. A investigação toma como ponto de partida as mudanças ocorridas na sociedade em geral, e nas mulheres em particular, desde a criação deste programa social pelo ex-presidente Luiz Inácio Lula da Silva, em 2003, que tinha como meta reduzir os efeitos da pobreza extrema no Brasil. Dessa forma, INFORMENTO consiste na combinação dos modelos metodológicos IDEIAS (Inclusão Digital e Educação Informacional para a Saúde) e AURA (Autorreforço Acompanhado). O primeiro permite construir as bases para a Alfabetização Informacional por meio dos indicadores que abordam o desenvolvimento de habilidades e competências no uso da internet como aprendizagem para a vida. Já o segundo modelo permite acompanhar o processo de empoderamento das mulheres em projetos de desenvolvimento por meio da criação de indicadores sociais em contextos específicos. Com a combinação de ambos foi possível averiguar ao mesmo tempo os conhecimentos informacionais e o processo de empoderamento e mensurá-los por meio dos níveis de 'saber', 'fazer', 'ter' e 'poder'. A pesquisa concluiu que o acesso a uma renda mensal como o Bolsa Família foi importante para que as mulheres entrevistadas pudessem acessar outros dispositivos da vida social e democrática como educação e saúde e, assim, construir e exercer a cidadania. Logo, foi um fator de empoderamento devido à abrangência de atuação institucional. No entanto, as conclusões também apontam a necessidade de desenvolver formação em 'Alfabetização Informacional para o empoderamento' como uma forma de contribuir para a autonomia, desenvolvimento e qualidade de vida das mulheres.

Palavras-chave: acesso à informação. Empoderamento. Cidadania. Programa Bolsa Família. políticas públicas de gênero. 


\section{Women and mothers of Bolsa Família: access to information, empowerment and citizenship in three communities in Sergipe (Brazil)}

Abstract: The objective of this work is to present the IINFORMENTO (Access to Information and Empowerment for Equality and Citizenship) methodological model developed in my doctoral thesis Women and mothers of the Bolsa Família Program: access to information, empowerment and citizenship: a study of three communities of Sergipe (2017) - to analyse the qualitative interviews. The starting point of the thesis concerns the changes that have taken place in society in general, and in women in particular, since the creation of this social program by former President Luiz Inacio Lula da Silva in 2003, which aimed to reduce the effects of extreme poverty in Brazil. In this way, INFORMENTO combines the methodological models IDEIAS (Digital Inclusion and Informational Education for Health) and AURA (Self-reinforced Accompaniment). The first model allows the building of bases for Information Literacy through indicators that approach the development of skills and competences in the use of the internet as learning for life. On the other hand, the second model allows us to follow the process of empowerment for women in development projects through the creation of indicators in specific contexts. The combination of the indicators of these models allowed us to ascertain the informational knowledge and empowerment process and to measure them through the levels of 'knowing', 'doing', 'having' and 'power'. The research concluded that access to a monthly income such as Bolsa Família was important for the women interviewed, because they gained access to other devices of social and democratic life, such as education and healthcare, and thus built and exercised their citizenship. Therefore, it was a factor of empowerment due to the scope of institutional action. However, the conclusions also point to the need to develop training in 'Information Literacy for Empowerment' as a way of contributing to the autonomy, development and quality of life of women.

Keywords: access to information. Empowerment. Citizenship. Bolsa Família Program. gender public policies.

\section{Mujeres y madres del programa Beca Familia: acceso a la información, empoderamiento y ciudadanía en tres comunidades de Sergipe (Brasil)}

Resumen: El objetivo de este trabajo es presentar el modelo metodológico IINFORMENTO (Acceso a la información y empoderamiento para la igualdad y la ciudadanía) desarrollado en la investigación titulada - Mujeres y madres del Programa Bolsa Família: acceso a la información, empoderamiento y ciudadanía: un estudio de tres Comunidades de Sergipe (2017) - con el propósito de analizar las entrevistas cualitativas usadas en la investigación. La investigación toma como punto de partida los cambios que han tenido lugar en la sociedad en general, y en las mujeres en particular, desde la creación de este programa social por el ex presidente Luiz Inácio Lula da Silva en 2003, cuyo objetivo era reducir los efectos de la extrema pobreza en Brasil. De esta forma, INFORMENTO combina los modelos metodológicos IDEIAS (Inclusión digital y Educación informacional para la salud) y AURA (Acompañamiento auto reforzado). El primer modelo permite la construcción de bases para la alfabetización de la información a través de indicadores que abordan el desarrollo de habilidades y competencias en el uso de Internet como aprendizaje para la vida. Por otro lado, el segundo modelo nos permite seguir el proceso de empoderamiento de las mujeres en proyectos de desarrollo a través de la creación de indicadores en contextos específicos. La combinación de los indicadores de estos modelos nos permitió determinar el conocimiento informativo y el proceso de empoderamiento y medirlos a través de los niveles de 'saber', 'hacer', 'tener' y 'poder'. La investigación concluyó que el acceso a un ingreso mensual como Bolsa Família era importante para las mujeres entrevistadas, porque obtuvieron acceso a otros factores de la vida social y democrática, como la educación y la atención médica, y de este modo construyeron y ejercieron su ciudadanía. Por lo tanto, fue un factor de empoderamiento debido al alcance de la acción institucional. Sin embargo, las conclusiones también apuntan a la necesidad de desarrollar la capacitación en 'Alfabetización informacional para el empoderamiento' como una forma de contribuir a la autonomía, el desarrollo y la calidad de vida de las mujeres.

Palabras clave: acceso a la información. empoderamiento. Ciudadanía. Programa Bolsa Familia. políticas públicas de género. 


\section{Introdução}

Pela primeira vez desde a Constituição de 1988, que está completando 30 anos, vivemos um retrocesso democrático na sociedade com relação a vários direitos garantidos pela Carta Magna. Este passo atrás trouxe consigo também um contexto repleto de discursos e práticas de misoginia, homofobia, racismo, preconceito contra os pobres e a classe trabalhadora e ataques aos direitos trabalhistas conquistados a partir da CLT (Consolidação das Leis Trabalhistas) e aprimorados pelo texto constitucional. Passados dezoito anos desde a entrada no novo milênio e depois de ter experimentado um significativo crescimento econômico e social, o país começou a enfrentar dificuldades econômicas e políticas.

Como se não bastassem os problemas com a incipiente crise econômica, concomitantemente iniciou-se também uma crise política sem precedentes, que culminou no golpe parlamentar, jurídico e midiático da presidenta Dilma Rousseff (2011-2016). O vazio institucional pós-golpe foi sendo preenchido por discursos eivados de todos os aspectos mencionados acima, acrescidos de sentimentos e palavras de ódio que mesclam, ademais, moralismo e fanatismo religioso. Tudo isto vindo de parlamentares que deveriam defender o Estado laico de direito, as leis e a democracia. Nunca Deus foi tão citado em um parlamento como a partir de 2016 o foi no Brasil.

Evidentemente este cenário não é exclusivo do nosso país. A América Latina, de um modo geral, vem sofrendo ataques à democracia, às mulheres, às políticas sociais e aos direitos humanos conquistadas nas últimas décadas e também aos novos direitos que ainda estão por conquistar, como é o caso da legalização do aborto, um capítulo à parte na luta feminista em países latino-americanos. Na vizinha Argentina, as mulheres protagonizaram em 2017 o movimento "Ni una a menos", que ganhou adeptas também em outros países. No Brasil, apesar dos avanços na legislação, ainda é muito alto o número de mulheres assassinadas diariamente, mas o pior é o desprezo que se tem pelas vítimas de assassinato e pelas delicadas questões relacionadas às mulheres como a violência doméstica, o aborto e a desigual remuneração entre homens e mulheres.

$\mathrm{O}$ ataque às mulheres por parte de um candidato de discurso fascista à presidência (que, apesar disto, ganhou as eleições para o maior cargo do Executivo) levou milhares em todo o Brasil e no exterior às ruas, num significativo ato pela manutenção da democracia, dos direitos sociais e humanos e contra a homofobia. Esta manifestação, a maior desde as 'Jornadas de Junho de 2013', foi protagonizada pelas mulheres, que usaram as redes sociais com a hashtag \#elenao, bem como grupos de discussão, sobretudo no Facebook e Whatsapp, para mobilizar 
outras mulheres Brasil afora, mostrando os diferentes usos da cultura digital na vida social. Esta forma generalizada e pulverizada de mobilização vem se tornando objeto de uma nova epistemologia feminista, chamada de ciberfeminismo (MARTINEZ, 2017).

Tal é o contexto em que apresentamos esta pesquisa, que tem como objetivo apresentar a metodologia INFORMENTO (Acesso à Informação e Empoderamento para a Igualdade de Gênero e a Cidadania). Desenvolvida em minha investigação Mulheres e mães do Programa Bolsa Família: acesso à informação, empoderamento e cidadania em três comunidades de Sergipe esta proposta metodológica analisa as entrevistas orais de mulheres sergipanas beneficiárias do Programa Bolsa Família (PBF) unindo indicadores que mensuram, ao mesmo tempo, habilidades e competências informacionais e o desenvolvimento social dos grupos por meio da autopercepção de mudanças subjetivas.

Dessa forma, utilizamos com o modelo IDEIAS (CUEVAS-CERVERÓ, 2009), cuja sigla significa Inclusão Digital e Educação Informacional para a Saúde, e o modelo AURA (CHARLIER; CAUBERGS, 2007), iniciais de Autorreforço acompanhado. O primeiro permite construir as bases para a Alfabetização Informacional por meio dos indicadores que abordam o desenvolvimento de habilidades e competências no uso da internet como aprendizagem para a vida. O segundo, possibilita acompanhar o processo de empoderamento das mulheres em projetos de desenvolvimento social por meio da criação de indicadores em contextos específicos.

Assim sendo, a combinação dos indicadores destes modelos gerou uma nova metodologia, que permitiu averiguar três grupos para os quais nem um nem outro, isoladamente, dariam conta. Unir os dois permitiu não só explorar as metodologias referidas acima como também criar novos indicadores metodológicos (INFORMENTO) para os grupos que estavam saindo de uma situação de vulnerabilidade em um contexto social, geográfico e cultural bastante particular. Dessa maneira, foi possível conhecer e entender ao mesmo tempo os seus conhecimentos informacionais e o processo de empoderamento ao mensurá-los por meio dos níveis de 'saber', 'fazer', 'ter' e 'poder'.

Se de um lado temos a grande mobilização \#elenao, forjado cem por cento na cibercultura, de outro, levando em consideração o baixo nível informacional das mulheres entrevistadas, deduzimos que talvez não tenham tido acesso a este movimento. Assim, ficam patentes as desigualdades entre gênero com relação ao acesso à informação, o que impede também outras possíveis leituras da realidade por parte das beneficiárias do Bolsa Família, sobretudo quando diz respeito aos seus direitos, à sua condição de mulher e ao conhecimento das políticas a serem implementadas por governos que podem, inclusive, retirar direitos já conquistados. 
Isto posto, este artigo se divide em duas partes. A primeira contextualiza o Programa Bolsa Família e as políticas públicas para as mulheres, implementadas nos governos Lula e Dilma. A segunda parte apresenta a metodologia INFORMENTO (RIOS, 2017), que foi utilizada para analisar as entrevistas orais feitas com as beneficiárias do PBF.

\section{- O Programa Bolsa Família}

Trata-se de um primeiro programa de transferência de renda condicionado feito para famílias em situação de extrema pobreza com renda per capta de até $R \$ \$ 85,00$ reais e em situação de pobreza com renda per capta entre $\mathrm{R} \$$ 85,01 e $\mathrm{R} \$ 170,00$. Criado em 2003, pelo presidente Luiz Inácio Lula da Silva por meio da Medida Provisória no 132, foi posteriormente convertido na Lei no $10.386 / 2004$, e tem como objetivo combater a fome, a pobreza, a exclusão social e melhorar a saúde nutricional e educacional das famílias em curto prazo. O PBF consistiu em unificar alguns programas existentes, transformando-se assim em um único benefício e tem como eixo a família, e não o indivíduo. Foi pensado para melhorar o capital humano, diminuindo a desigualdade intergeracional.

É o primeiro programa de transferência de renda não contributivo do país (custo corresponde a 0,5\% do PIB - Produto Interno Bruto) e, devido ao seu alcance, foi considerado o maior do mundo. No momento de produção deste artigo, o programa alcança 13,7 milhões de famílias em todo o país, o que equivale a aproximadamente um terço da população. Desse número, 93\% dos titulares são mulheres. "O cartão magnético e a priorização dada à mulher como titular proporcionaram o empoderamento feminino em espaços públicos" (CAMPELLO, 2013, p. 18). Os impactos desse programa são visíveis em diversos aspectos: no econômico, pois movimenta as economias locais; na saúde e nutrição infantil, uma vez que fortalece o capital humano tanto das crianças como das mães; na educação, pois melhorou sensivelmente a frequência escolar; e no social, já que reduziu o trabalho infantil, pois agora os pais têm uma renda fixa, retirando das crianças parte da 'responsabilidade'.

A 2a Rodada de Avaliação de Impacto do PBF, feita em 2012, aponta que há entre as beneficiárias maiores taxas de vacinação; 1,5 consultas pré-natal a mais comparadas com as não beneficiadas do mesmo perfil e redução da mortalidade infantil até cinco anos em municípios com alta cobertura. Além disso, de acordo com o relatório, há melhores condições habitacionais, otimismo em relação ao bem-estar das famílias, maior frequência e progressão escolar, melhoria na qualidade dos cuidados de saúde recebidos por mulheres grávidas e maior poder de decisão das mulheres no ambiente domiciliar.

É importante ressaltar que esses aspectos dizem respeito aos resultados das contrapartidas que as mães e mulheres beneficiadas têm que dar ao Estado. Nessa relação de troca, elas passam a ter acesso à informação nas áreas de saúde, educação e assistência social, o que aumenta a sua autoestima, bem-estar e percepção de cidadania. 
Outra pesquisa posterior, feita pelo Ipea (Instituto de Pesquisa Econômica Aplicada) mostra que, entre 2002 e 2012, a quantidade de brasileiros em situação de pobreza foi reduzida a um ritmo de $10,4 \%$ ao ano, o que implica em uma diminuição total de $63,3 \%$. Nesse mesmo período, houve uma redução de $54,9 \%$ na desigualdade devido à contribuição da renda do trabalho formal, enquanto o Bolsa Família foi responsável por $12,2 \%$ dessa queda, mostrando que tem um forte impacto sobre a desigualdade.

\section{- Políticas públicas para as mulheres}

Até o ano de 2003, as políticas de gênero no Brasil se limitavam às Casas Abrigo e às Delegacias da Mulher. Estas representaram um avanço muito grande, pois dava à mulher agredida um espaço que não lhe era hostil. As políticas, no entanto, não avançaram naquele momento e, além disso, enfocavam o problema da violência contra a mulher de um único ponto de vista - o da violência física em si -, sem levar em consideração as soluções a médio e longo prazos.

A partir desta data, no entanto, conforme consta no quadro 1, começam a haver algumas mudanças. Em janeiro de 2003, três dias depois da posse de Lula como presidente, é criada a Secretaria de Políticas para as Mulheres da Presidência da República e, em março, a Secretaria de Políticas de Promoção da Igualdade Racial. Em 2013, houve uma fusão das duas com a formação de mais uma pasta, a do Ministério das Mulheres, da Igualdade Racial e dos Direitos Humanos (MMIRDH).

Quadro 1 - Quadro das políticas para as mulheres criadas nos governos de Lula e Dilma Rousseff

\begin{tabular}{ll}
\hline 2003 & $\begin{array}{l}\text { Criação da Secretaria Especial de Políticas Públicas para as Mulheres da Presidência da República } \\
\text { (com status de ministério) } \\
\text { Lei de Notificação Compulsória (Lei 10.778/03) dos casos de violência contra as mulheres que } \\
\text { forem atendidas em serviço de saúde pública ou privada }\end{array}$ \\
I Conferência Nacional de Políticas Públicas para as Mulheres \\
I Plano Nacional de Políticas Públicas para as Mulheres \\
Criação do Ligue 180, gratuito, para orientações sobre direitos e serviços públicos para a \\
população feminina em todo o país \\
2006 & Criação da Lei 11.340, conhecida como Lei Maria da Penha \\
2007 & II Conferência Nacional de Políticas Públicas para as Mulheres \\
2008 & Pacto Nacional pelo Enfrentamento à Violência contra as Mulheres \\
2013 & II Plano Nacional de Políticas Públicas para as Mulheres \\
2014 & Programa Mulher: Viver sem violência \\
\hline 2015 & O Ligue 180 é transformado em Disque Denúncia \\
\hline
\end{tabular}

Fonte: Dados da pesquisa. 
Desse quadro 1, destacaremos dois marcos legais principais: a Lei 11.340, de 2006, mais conhecida como Lei Maria da Penha, que reconhece como crime a violência contra as mulheres, e a Lei 13.104 (2015) conhecida como Lei do Feminicídio.

De acordo com o livreto Maria da Penha (2015), 98\% da população brasileira conhece esta lei e $66 \%$ das mulheres afirmam que se sentem mais seguras com ela. Do conjunto de políticas da América Latina para combater a violência de gênero, esta lei de proteção é considerada a mais completa e uma das três melhores do mundo, pois reconhece a violência de uma maneira mais ampla, não apenas na sua forma física, e abrange, segundo seu artigo 50, "qualquer ação ou omissão baseada no gênero que the cause morte, lesão, sofrimento físico, sexual ou psicológico e dano moral ou patrimonial". O Supremo Tribunal Federal (STF) entende que, uma vez feita a agressão, esta torna-se um delito de caráter público. Em 2016 a Lei Maria da Penha completou dez anos de existência. De acordo com o Ipea, o impacto na redução de homicídio doméstico foi de $10 \%$ após a sua aplicação. Mesmo assim, ainda é alto o índice de violência e de mortes, o que demonstra que ainda falta muito a ser feito nesse campo em termos de políticas de gênero para que mude a cultura machista.

Os movimentos feministas do Brasil conseguiram avançar ainda mais em políticas legais de proteção à mulher e combate à violência com a Lei do Feminicídio, que é o termo usado quando a causa do crime se dá pela condição de ser mulher. "Suas motivações mais usuais são o ódio, o desprezo ou o sentimento de perda do controle e da propriedade sobre as mulheres, comuns em sociedades marcadas pela associação de papéis discriminatórios ao feminino, como é o caso brasileiro" (Dossiê Violência Contra as Mulheres, 2015).

Dessa forma, enquanto a Lei Maria da Penha reconhece o crime cometido contra a mulher dentro do contexto doméstico e familiar (violência física, psicológica, moral, sexual e patrimonial) a Lei do Feminicídio trata de qualificar o crime cometido contra a mulher pela sua condição de gênero. Ao qualificá-lo, a pena do criminoso é dobrada, seja ele do sexo masculino ou feminino, uma vez que a lei também reconhece as relações homoafetivas entre mulheres. Se fosse qualificado como homicídio, a punição seria de 6 a 20 anos, já com a qualificação de feminicídio, a pena passa de 12 a 30 anos de cárcere.

De acordo com a Comissão Parlamentar Mista de Inquérito sobre Violência contra a Mulher (2013, p. 1003),

O feminicídio é a instância última de controle da mulher pelo homem: o controle da vida e da morte. Ele se expressa como afirmação irrestrita de posse, igualando a mulher a um objeto, quando cometido por parceiro ou ex-parceiro; como subjugação da intimidade e da sexualidade da mulher, por meio da violência sexual associada ao assassinato; como destruição da identidade da mulher, pela mutilação ou desfiguração de seu corpo; como aviltamento da 
dignidade da mulher, submetendo-a a tortura ou a tratamento cruel ou degradante.

Durante o governo de Dilma Rousseff foi criada uma Rede Nacional de Enfrentamento à Violência contra a Mulher, que tem no Disque Denúncia seu canal de comunicação entre a mulher agredida e o poder público.

\section{Metodologia - Apresentação do Modelo metodológico INFORMENTO}

Desenvolvida na minha tese doutoral (RIOS, 2017), a metodologia de pesquisa INFORMENTO analisa as falas de mulheres com base nas categorias acesso à informação e empoderamento. Esta metodologia é resultado da junção dos modelos IDEIAS e AURA. Enquanto IDEIAS enfoca os aspectos informacionais e documentais de inclusão digital para a cidadania, traça o perfil dos sujeitos a serem investigados e é utilizado para a formação em Alfabetização Informacional (ALFIN); o segundo modelo busca criar indicadores de acompanhamento de empoderamento a partir de programas de desenvolvimento (no nosso caso, o Bolsa Família), medindo o empoderamento a partir dos indicadores "ter", "saber", "querer", "poder" para acompanhar as mudanças nos sujeitos investigados.

A combinação dos dois modelos, portanto, resultou na criação de novos indicadores que culminaram na proposta "ALFIN para o empoderamento", um processo de aprendizagem que se dá ao longo da vida unindo novos conhecimentos adquiridos e ação, numa relação dialógica e prática.

Nos indicadores constantes do quadro 2, foram exploradas questões objetivas e subjetivas que relacionam os impactos e avanços profissionais e informacionais com a categorias teóricas de empoderamento, reconhecimento social e cidadania para construir indicadores de transformação social num contexto socioeconômico e cultural específico. Estes indicadores, igualmente, podem ser aplicados a outros projetos de desenvolvimento social em contextos similares. 
Quadro 2 - Indicadores de impactos de acesso à informação e empoderamento aplicado às beneficiárias do Bolsa Família baseado nos Modelos IDEIAS e AURA

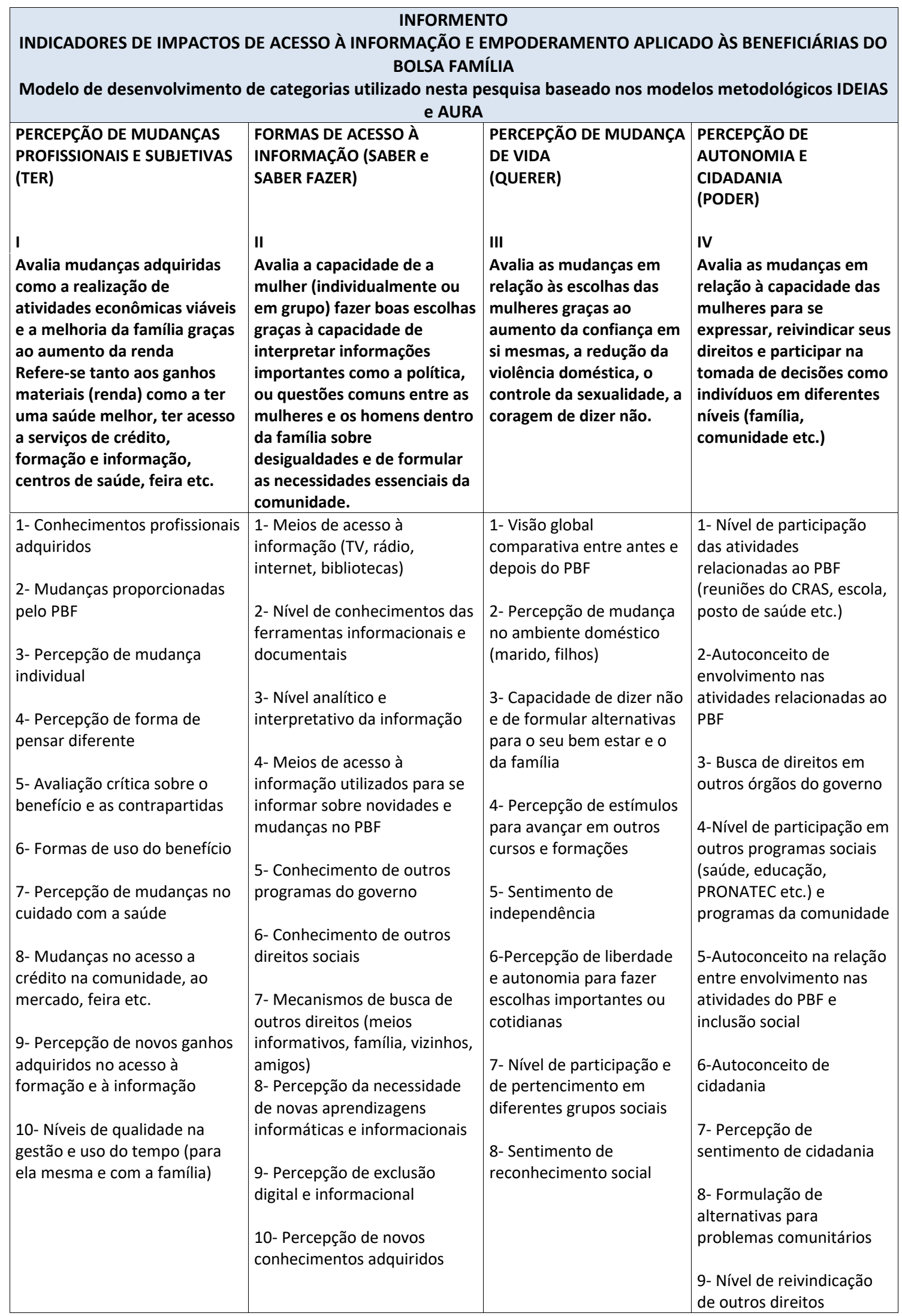

Fonte: Elaboração própria. 


\subsection{Percepção de mudanças profissionais e subjetivas - TER - CATEGORIA I}

Neste item desenvolvemos as falas a partir de cada indicador acerca dos aspectos profissionais relacionadas principalmente ao processo de aprendizagem. Estes aspectos se destacam nas narrativas e, a partir daí, é possível perceber também a estreita relação entre o empoderamento individual e coletivo (CHARLIER; CAUBERGS, 2007) e as mudanças adquiridas depois do PBF. Destacam-se, por exemplo, atividades viáveis economicamente, ganhos para a família em termos de benefícios (escolaridade dos filhos, cuidados pessoais, novas aprendizagens).

As falas relatam, para além dos aspectos visíveis, a importância dos espaços físicos de construção e fortalecimento da cidadania (o Centro de Referência de Assistência Social - CRAS, sendo o principal deles) como mediador dos processos de empoderamento, uma vez que ajuda a superar os quadros de conflitos de gênero e doméstico por meio de programas. As atividades de aprendizagem como oficinas, cursos e palestras vão construindo sentidos e significados sociais nunca antes experimentados por várias das mulheres entrevistadas devido a uma carência de convívio durante toda a vida, uma vez que viviam antes confinadas apenas às tarefas domésticas.

Abriremos as análises das falas destacando inicialmente no quadro 3 os indicadores e o modelo metodológico (AURA, IDEIAS ou AURA/IDEIAS) no qual se encaixam. Os indicadores não aparecem em sequência, mas na ordem em que surgem nas falas. Para este artigo, por questão de espaço, selecionamos apenas uma fala de cada categoria.

Quadro 3 - Indicadores da categoria "ter"

\begin{tabular}{|l|l|}
\hline Indicadores & Modelo \\
\hline 1-Conhecimentos profissionais adquiridos & AURA \\
\hline 2- Mudanças proporcionadas pelo PBF & AURA \\
\hline 3- Percepção de mudança individual & AURA \\
\hline
\end{tabular}

Fonte: Elaboração própria

Dentro desta categoria, a fala de Andaraí Bárbara, aos 56 anos, abarca três indicadores. Em seu caso específico, revela uma mudança/melhora com relação à sua saúde (indicador 3 ). Ela recebe o PBF devido ao fato de criar o neto, cuja guarda Ihe foi dada pela justiça após a morte do seu filho, pai da criança. Recém-saída de uma depressão, a única maneira de 'escapar' da doença foi frequentar os cursos e as atividades do grupo de mães (indicador 2). Nesta fala, fica 
patente a sua consciência da importância e da necessidade acesso à informação e à formação (indicador 1):

Os cursos ajudaram a ter conhecimento. O computador eu só ficava olhando e agora não, eu sei ligar e desligar, sabe, eu quero continuar fazendo pra avançar mais, sabe, ficar mais por dentro, porque eu pego mas ainda não me sinto firme, eu tenho dúvida, aí eu chamo o meu menino de 17 anos, ele nunca fez o curso de informática, mas mexe em tudo, digo, venha aqui, me dê uma luz aqui, ai eu olho. Eu quero me sentir ainda firme. (Andaraí Bárbara, 56 anos, Nossa Senhora do Socorro).

As falas desta categoria, de um modo geral, apontam para diferentes mudanças tanto em termos monetários como de aprendizagem. Demonstram, em certa medida, os impactos imediatos do programa de uma forma pessoal e familiar na medida em que relatam a sua percepção e práticas concretas com relação à saúde, à escola e o cuidado e atenção com a família.

\subsection{Formas de Acesso à informação - Saber e Saber Fazer (CATEGORIA II)}

Com o Modelo AURA, é possível avaliar a partir do seu conhecimento informático e informacional a sua capacidade de fazer escolhas, interpretações importantes no âmbito da política ou, neste caso, do funcionamento dos organismos sociais, e também da família (saber). Também evidencia a sua percepção sobre as desigualdades e de formular alternativas na família e na sociedade, aspectos que se relacionam diretamente com saber-fazer (desdobramento da categoria saber), que é a capacidade de agir de acordo com o problema apresentado. Dessa forma, conforme o quadro 4, os modelos AURA e IDEIAS estão presentes nesta categoria, já que a combinação dos seus indicadores neste trabalho foi essencial para compreender como o acesso à informação tem sido importante para o desenvolvimento cognitivo e subjetivo das mulheres, fator essencial para o desenvolvimento das outras categorias de empoderamento.

Quadro 4 - Indicadores da categoria "saber"

\begin{tabular}{|l|l|}
\hline \multicolumn{1}{|c|}{ Indicadores } & \multicolumn{1}{c|}{ Modelo } \\
\hline 1- Meios de acesso à informação (TV, Rádio, internet) & IDEIAS \\
\hline 10- Novas aprendizagens adquiridas & IDEIAS \\
\hline 3- Capacidade de interpretar informações importantes & IDEIAS/AURA \\
\hline
\end{tabular}

Fonte: Elaboração própria. 
As falas expostas aqui nesta categoria, de um modo geral, procuraram destacar o processo de mudança proporcionado pelo PBF em diferentes aspectos, sobretudo em relação ao acesso às novas formas de ganhos por meio do acesso à formação e à informação (conhecimentos adquiridos ou por adquirir). Destacaram-se a percepção da necessidade de adquirir novas aprendizagens e ao mesmo tempo o entusiasmo com a descoberta de novos conhecimentos, como no caso de Andaraí Bárbara. $\mathrm{O}$ acesso à informação permite o acesso a outros direitos sociais.

Esta categoria revelou a existência da capacidade de interpretar as informações que são importantes, não só para cada uma como para os grupos dos quais fazem parte. Mas mostrou também que há múltiplas potencialidades neste aspecto se o seu uso se fizer com mais propriedade em termos de capacitação por parte não só destas mulheres aqui entrevistadas como também de outras em situação semelhante.

\subsection{Percepção de Mudança de vida - Querer - (CATEGORIA III)}

Este tópico desenvolve as falas sobre percepção de mudança que estão relacionadas com os conceitos de empoderamento e reconhecimento. Explora as questões relacionadas com as escolhas resultantes da sua autodeterminação e autoconfiança, que se traduzem na redução da violência doméstica e na coragem de dizer não.

Quadro 5 - Indicadores da categoria "querer"

\begin{tabular}{|l|l|}
\hline \multicolumn{1}{|c|}{ Indicador } & \multicolumn{1}{c|}{ Modelo } \\
\hline 1- Visão global comparativa entre antes e depois & AURA \\
\hline
\end{tabular}

Fonte: elaboração própria

Marilene Santana, neste momento da sua fala, menciona os maus tratos sofridos com a violência do marido e lembra a Lei Maria da Penha (que protege as mulheres vítimas de violência doméstica). Ela diz que no tempo em que o marido lhe batia, a lei ainda não existia, e que tudo poderia ter sido diferente. Ao mesmo tempo em que demonstra uma visão ampla, global entre um antes e um depois (indicador 1), no entanto, também faz uma interpretação crítica e contundente da aplicação da lei:

Eu nem sei, agora, porque pra mim agora não vale de nada, porque antigamente não existia. Era muita pancada. E ninguém tinha lei de nada. Agora pra umas coisas foi boa, mas pra outras... Vai, dá queixa, quando chega lá, não sei quantas distância tem que ter do homem. Quando pensa que não, pancada outra vez, aí não é lei. "Você vai dar uma cesta básica a ela", isso não é lei. Quando você sai dali, sai com medo do mesmo jeito. Ou pior. No meu 
tempo, se existisse essa lei Maria da Penha eu acho que eu não estaria hoje com meu marido. Passei 44 anos com ele e não desejo para as minhas piores amigas. Se fosse agora com essa lei Maria da Penha talvez fosse bom pra mim. (Marilene Santana de Jesus, 60 anos, São Cristóvão).

Nesta categoria (QUERER), de uma maneira geral, elas ainda estão num processo de mudança e precisam de muito apoio institucional para ajudar a concretizar os seus ideais. Elas querem se profissionalizar, aprender novos cursos, trabalhar, sentir-se seguras, ter independência e liberdade, uma vida familiar pacífica, dignidade, ter conhecimento e reconhecimento e ser valorizadas dentro e fora de casa.

De acordo com Charlier e Caubergs (2007), as instituições têm influência sobre o desenvolvimento do "saber", "ter", "querer" e "poder" dos indivíduos e suas organizações. A família, por exemplo, tem uma influência importante sobre o desenvolvimento da autoconfiança e da imagem que o indivíduo tem de si mesmo; as organizações não governamentais influenciam o desenvolvimento dos conhecimentos dos indivíduos e suas organizações; o Estado, por sua vez, tem influência sobre a possibilidade de organização e de consolidar seu poder social. Por outro lado, os indivíduos e suas organizações (agrupações, associações) podem ter influência nas instituições da sociedade e contribuir para a sua transformação (CHARLIER; CAUBERGS, 2007 , p. 14). É, portanto, um círculo virtuoso em que umas instituições têm mais ou menos influência em torno dos níveis de ter, saber, querer e poder.

Num nível individual, as falas apontam para a autoconfiança e construção de uma vida pacífica em que possam escolher e ter controle sobre seus corpos sem imposições ou dominações físicas e/ou psicológicas. Em outras palavras, buscam adquirir qualidade de vida. Num nível coletivo, indicam a capacidade e a coragem de dizer não, de dar um basta a situações de dominação e opressão e, dessa forma, sinalizam para um reforço da justiça social devido à busca da igualdade de gênero.

\subsection{Percepção de autonomia e cidadania - Poder - (CATEGORIA IV)}

Neste item, o sentimento do que é ser cidadã enlaça todas as diferentes falas. Aqui, podemos acompanhar as mudanças em relação à sua capacidade e autonomia na hora de expressar-se e reivindicar seus direitos no âmbito familiar, social e comunitário. As respostas sobre a pergunta "o que é ser cidadão?" dizem respeito a um marco temporal específico: o momento em que começaram a receber o PBF e ao processo de aprendizagem. Perguntamonos, então: como era antes disso?

Analisando o que Ihes ocorreu em termos de mudança exterior (desenvolvimentos objetivos) e interior (desenvolvimentos subjetivos), percebemos que antes essas pessoas eram privadas não só de exercerem a cidadania como um direito, mas também da própria consciência 
cognitiva. Isso está nas falas como "estudei isso", eu fiz um trabalho sobre esse assunto, "eu assisti a uma palestra sobre cidadania", como se o direito estivesse descolado.

\begin{tabular}{|l|l|}
\multicolumn{2}{|c|}{ Quadro 6 - Indicador da categoria “poder” } \\
\begin{tabular}{|c|c|}
\hline Indicador & Modelo \\
\hline 7- Percepção do sentimento de cidadania & AURA \\
\hline
\end{tabular}
\end{tabular}

Fonte: Elaboração própria

Débora, de 29 anos, nos dá uma dimensão do sentimento de respeito e valorização a partir do momento em que passou a receber o benefício, algo nunca experimentado antes.

Assim, como cidadã, eu me senti mais respeitada. Minha filha mais velha tem 12 anos, e eu nunca recebi o benefício. Sempre dava entrada e nunca tinha, porque ela estudava em colégio particular, graças a Deus a gente tinha umas condições boas, porém na época eu sei que eu precisava mais pra ela mesma. Mas agora eu me senti respeitada como cidadã, eu dei entrada e logo recebi, não demorou e já incluí também a minha menina, ela não está mais em escola particular, tá em escola pública. Então eu gostei por causa disso, me senti mais valorizada. É como seu estivesse assim com o meu direito realmente assegurado. Como se eu fosse atrás de algo e eu tive um retorno, porque é difícil a gente ir atrás de algo assim e receber um retorno. (Débora dos Santos, 29 anos, Barra dos Coqueiros).

A maioria das vezes as pessoas sentem certo "cansaço social" decorrente de um busca vã dos seus direitos. Mas não foi o que lhe aconteceu desta vez. A sua fala mostra a percepção do sentimento de cidadania e pertencimento, ao sentir-se socialmente incluída (indicador 7).

\section{Conclusões}

As falas das entrevistadas mostram um processo que diz respeito aos mecanismos de empoderamento das categorias mencionadas. Podemos afirmar que esse processo pelo qual as mulheres passaram até agora resultou em um salto substancial em termos subjetivos e de autonomia pessoal a partir da renda fixa que, apesar de baixo valor, se revelou fundamental para minimizar as desigualdades no âmbito familiar. Além disso, retirou-as de casa e levou-as ao espaço público.

Quanto à cidadania, podemos perceber é construída no dia a dia, nas reivindicações, cobranças e na busca de outros órgãos para a solução dos problemas. Mas sobretudo se revela no sentimento de pertencimento comunitário, social e pessoal. Ainda é um requisito democrático que está se constituindo enquanto práxis e autoconstrução. O mais importante, entretanto, é que a palavra cidadania agora faz parte do vocabulário dos grupos entrevistados. Foi possível perceber que, na prática, elas Ihe deram um significado bem amplo, que vai desde 
ações prosaicas do cotidiano a práticas menos corriqueiras, algumas bem sucedidas, e que estimulam o seu exercício em outros contextos.

O Estado finalmente criou políticas de reconhecimento dessa parcela da população que antes era invisível, destituída de quase todos os direitos (exceto o direito do voto) fazendo emergir praticamente uma nova classe social por meio do acesso a 'velhos' direitos como a educação e a saúde. Taylor (2009), em diálogo com Kant, relaciona a dignidade humana com a autonomia que, para este autor alemão, significa a capacidade de casa pessoa de determinar por si mesma a sua ideia de uma boa vida. Curiosamente, uma das nossas entrevistadas, Iolanda Meneses, relacionou cidadania com dignidade, que é a sua percepção para se ter uma boa vida e para ser reconhecida: Ser uma pessoa cidadã é ter também os meus direitos, os valores. Tipo dignidade.

Do nosso ponto de vista, ficou demonstrado que a inclusão das mulheres no PBF e o acesso à informação e à capacitação profissional foram fundamentais para a transformação das realidades das mulheres dos três grupos entrevistados. A adaptação das metodologias IDEIAS e AURA, ao mesmo tempo que nos permitiu saber os seus conhecimentos informáticos e documentais, com os avanços e limitações, também permitiu um conhecimento das suas subjetividades, dimensão importante enquanto constituição do sujeito social e político que compõe a construção da autonomia e da cidadania. Inferimos que foram acionados os dispositivos das transformações pessoal e coletiva. Resta saber se, diante das mudanças políticas e sociais que vêm ocorrendo no Brasil, essas mulheres poderão continuar procurando um lugar ao sol.

\section{Referências}

BRASIL. CONGRESSO NACIONAL. Comissão Parlamentar Mista de Inquérito. Brasília: Senado Federal, 2013.

BRASIL. MINISTÉRIO DO DESENVOLVIMENTO SOCIAL E COMBATE À FOME. SECRETARIA DE AVALIAÇÃO E GESTÃO DA INFORMAÇÃO. Avaliação de Impacto do Bolsa Família - 2a Rodada (AIBF II). Sumário Executivo. Brasília: Ministério do Desenvolvimento Social e Combate à Fome, 2012. Disponível em: <https://fpabramo.org.br/acervosocial/wpcontent/uploads/sites/7/2017/08/475.pdf>. Acesso em: 24 mar. 2019.

CAMPELLO, Teresa. Uma década derrubando mitos e superando expectativas. In.: CAMPELLO, Teresa; NERI, Marcelo. Programa Bolsa Família - Uma década de inclusão e cidadania. Brasília: Ipea, 2013. p. 15-24.

CASTELLS, Manuel. Ruptura. A crise democrática liberal. Rio de Janeiro: Zahar, 2018.

CHARLIER, Sophie; CAUBERGS, Lisette. El proceso de empoderamiento de las mujeres. Guía Metodológica. Bruxelas: Comisión de Mujeres y Desarrollo, 2007. 
CUEVAS-CERVERÓ, Aurora. IDEIAS - Inclusión Digital y Educación Informacional para la Salud. Madrid: Universidad Complutense de Madrid, 2009.

DARNTON, Robert; DUHAMEL, Olivier. Democracia. Rio de Janeiro: Record, 2001.

IPEA. Duas décadas de desigualdade e pobreza medidas pela PNAD/IBGE. Comunicados do Ipea, $\quad$ n. $159 . \quad$ Brasília: Ipea, 2013. Disponível em: $<$ http://www.ipea.gov.br/portal/images/stories/PDFs/comunicado/131001 comunicadoipea1 59.pdf $>$. Acesso em: 20 Out. 2018.

IPEA Atlas da violência 2018. Ipea/Fórum Brasileiro de Segurança Pública: Rio de Janeiro, 2018. Disponível

em: $<$ http://www.ipea.gov.br/portal/images/stories/PDFs/relatorio institucional/180604 atlas da violencia 2018.pdf>. Acesso 22 Out. 2018.

MARTINEZ, Fabiana. O conhecimento feminista na era digital: grupos de discussão do Facebook como uma nova epistemologia do conhecimento. Seminário internacional Fazendo Gênero 11 \& 13 Women's Worlds Congress, 2017. Anais Eletrônicos. Florianópolis, 2017.

NATANSOHN, Graciela. (Org.). Internet em código feminino: teoria e práticas. Buenos Aires: La Crujía Ediciones, 2013. Disponível em: <https://goo.gl/r1ZzmW>. Acesso em: 3 out. 2018.

REGO, Walquíria; PINZANI, Alessandro. Vozes do Bolsa Família. Autonomia, dinheiro e cidadania. 2. ed. São Paulo: Unesp, 2014.

RIOS, Acácia. Mulheres e mães do Programa Bolsa Família: acesso à informação, empoderamento e cidadania. Um estudo de três comunidades de Sergipe (Brasil). Tese de Doutorado, Programa de Investigação Biblioteca e Sociedade, Universidade Complutense de Madrid, 2017.

TAYLOR, Charles. El multiculturalismo y la política del reconocimiento. 2. ed. México: FCE, 2009. 